\title{
A inovação nos serviços como instrumento para a Inovação Social: uma visão integrativa
}

\author{
Services innovation as a tool to social \\ innovation: an integrative vision
}

\begin{abstract}
ANITA KON*, **
RESUMO: Baseado nas premissas do campo de estudos proposto pela Comissão Europeia nomeado como Inovação Social, o artigo examina o papel da inovação nos serviços como instrumento para o atendimento mais eficiente de demandas sociais, através de atividades intangíveis estatais e privadas, em resposta à complexidade das inter-relações e agentes envolvidos neste objetivo social. Apresenta uma visão das características diferenciadas da inovação nos serviços como um todo e da inovação social específica. Em seguida apresenta uma visão dos aspectos teóricos dos processos de organização e operacionalização nos serviços sociais, que derivam das inovações em serviços como um todo. Finalmente, examina o papel das redes de informação no aumento da eficiência e eficácia do atendimento das demandas sociais, através da inovação nos serviços.
\end{abstract}

PALAVRAS-CHAVE: Inovação; Serviços; Inovação social; Serviços estatais; Redes; Informática.

ABSTRACT: Based on premises of the new field of studies proposed by the European Commission named as Social Innovation, the article examines the role of innovation in services as a tool for a more efficient attendance of social demands, through new forms of state and private intangible activities, in response to the complexity of the interrelationships and agents involved in this social objective. It presents concepts about the differentiated characteristics of innovation in services as a whole, and of specific innovation in social services. Then, it analyzes the theoretical aspects of organization and operationalization processes in social services. Finally, it examines the role of the new environment created by information networks in increasing the efficiency and effectiveness of attending social activities, mainly through innovation in services.

KEYWORDS: Innovation; Social Innovation; Services; Commons; Neo-Schumpeterian Economy.

JEL Classification: O35; L8.

\footnotetext{
* Professora Titular da Pontifícia Universidade Católica de São Paulo, SP - Brasil.

* Coordenadora do Grupo de Pesquisas em Economia Industrial, Trabalho e Tecnologia/PUCSP, SP Brasil. anitakon@pucsp.br Submetido: 7/Março/2017; Aprovado: 21/Dezembro/2017.
} 


\section{INTRODUÇÃO}

O cenário de inovação que prevaleceu durante décadas na teoria econômica tradicional tinha como foco o contexto das indústrias manufatureiras e da agricultura, enquanto os serviços mantiveram sua posição subordinada a essas atividades. Essa abordagem considera que os serviços adotam as inovações tecnológicas criadas pela indústria manufatureira, mas produzem poucas inovações em seu próprio contexto, e assim permanecem com desempenho inferior na geração de valor agregado e seus empregos são pouco qualificados.

No entanto, essa ideia começou a ser questionada mais recentemente, uma vez que, com base em uma visão schumpeteriana, envolve muitas contradições inerentes. Como salientam Gallouj e Djellal (2010, p. 6), nas economias atuais a visão tradicional é posta em discussão por investigações empíricas profundas que identificaram intensa inovação nas atividades de serviços, inclusive nos setores que não têm lucro, ou seja, nos de serviços sociais e nos públicos.

Por sua vez, nas últimas décadas, as sociedades vêm enfrentando consideráveis problemas sociais como resultado do esgotamento dos modelos econômicos, cujos instrumentos tradicionais de política governamental começaram a se mostrar inadequados e as soluções de mercado nem sempre conseguiram resolver essas questões, ao mesmo tempo em que o crescimento dos custos governamentais para lidar com a provisão de serviços públicos tornaram-se incompatíveis com o orçamento disponível. As novas respostas a estas questões procuram atender às demandas sociais através da inovação, para criar novas formas de relacionamentos ou parcerias que impliquem retornos sociais crescentes e assim estimulem políticas públicas mais eficazes e eficientes.

Nesse contexto, a União Europeia criou em 2010 uma comissão que vem desenvolvendo grupos de estudos no campo que denominaram Inovação Social, que examinam as formas de ações de inovação voltadas para o atendimento das demandas sociais, a fim de criar novas ideias para a promoção de crescimento econômico e social, bem como de geração de trabalho. Estes conceitos são reunidos em documentos de apoio aos países que compartilham e disseminam informações sobre a inovação social na Europa, no intuito de estimular a criação de projetos que visando mobilizar investimentos governamentais e privados para estes objetivos (EU, 2010). Dessa forma, estas ações - que são associadas à iniciativa privada, governamental e de organizações não governamentais (ONGs) - se referem a novas estratégias, conceitos e organizações que atendam a necessidades sociais e constituem no processo de inventar, assegurar apoio e implementar novas soluções para necessidades e problemas sociais.

Assim, surgiram as novas visões para resolver estes problemas sociais, com base na combinação entre modelos tradicionais de ação e processos inovadores mais amplos para enfrentar novos desafios sociais (BEPA, 2011). Embora ainda não totalmente compreendidas em sua relação com as inovações de serviços, des- 
taca-se uma série de novas formas de ação inovadora, voltadas para a solução de questões da sociedade como um todo, cujos efeitos sociais são mais intensos do que aqueles puramente voltados para mercados econômicos.

Este artigo tem como objetivo investigar, através de uma visão integrativa, o papel da inovação em serviços, entre as novas formas de inovação apoiadas por tecnologia da informação e outras atividades intangíveis, em resposta à complexidade das inter-relações e agentes envolvidos no objetivo social, examinando particularmente sua relevância na área de serviços públicos, sejam estatais, privados ou não mercantis. Apresenta primeiramente os aspectos conceituais das premissas da denominada Inovação Social, bem como da inovação específica nas atividades de serviços como um todo, para continuar em seguida com a análise dos processos de inovação nos serviços sociais. A última seção examina o ambiente criado pela evolução da tecnologia da informação e o papel das redes de informação no aumento da eficiência e eficácia das inovações sociais especificamente através da inovação nos serviços.

\section{A NATUREZA DA INOVAÇÃO NOS SERVIÇOS E DA INOVAÇÃO SOCIAL}

Nas últimas décadas, uma série de crises econômicas levou as sociedades a enfrentar consideráveis problemas sociais como resultado do esgotamento dos modelos econômicos, cujos instrumentos tradicionais de política governamental começaram a se mostrar inadequados. Em alguns países, particularmente menos desenvolvidos, a estrutura de governança e os mecanismos governamentais tornaram-se incapazes de suprir satisfatoriamente a crescente demanda por serviços sociais resultante do elevado crescimento populacional. Ao mesmo tempo, observou-se que as soluções de mercado não conseguiram resolver estas questões e o crescimento dos custos do governo para lidar com a prestação de serviços tornaram-se incompatíveis com o orçamento disponível.

No entanto, o desenvolvimento da tecnologia no período, em particular da informática, permitiu o florescimento de novos paradigmas e novas ideias, o que foi possibilitado pela ênfase no conhecimento como um insumo relevante nos processos socioeconômicos e pelo fato de tornarem-se disponíveis tanto para o setor privado quanto para o governamental. As inovações associadas à mudança tecnológica tangível e intangível começaram a combinar modelos tradicionais com os novos paradigmas da informação, dando origem ao que alguns autores chamam de Economia Social - voltada para as questões sociais da economia - dada suas diferentes características em relação a economias baseadas na produção e consumo de bens através do mercado (Murray, Caulier-Grice e Mulgan, 2010).

A União Europeia definiu esse novo campo de estudos, conceituando as ações da Inovação Social como novas ideias que atendem a necessidades sociais, criam relacionamentos sociais e formam novos meios de colaborações entre os agentes 
envolvidos. Estas inovações podem incorporar produtos, serviços ou modelos criados para solucionar as questões relacionadas às demandas populacionais de modo mais eficaz e eficiente (EU, 2010).

A Inovação Social, que abrange a realização de ações públicas, privadas e de ONGs, está assim orientada para a resolução de problemas exigidos pelos novos paradigmas de desenvolvimento das economias. A maneira de criar soluções - desde o diagnóstico da questão a ser resolvida, a idealização da ideia a ser aplicada, o planejamento das ações a serem implementadas, até sua disseminação, monitoramento e controle - está representada em sua maioria por inovações em atividades intangíveis. Dessa maneira, a compreensão da inovação social está fortemente inserida no contexto da inovação nas atividades dos serviços em seu amplo espectro, e mais especificamente dos serviços sociais.

A investigação sobre a inovação social aqui empreendida foca primeiramente a inovação em atividades de serviços de forma ampla e, em particular, da inovação em atividades intangíveis voltadas para os serviços públicos estatais, privados e de organizações sem fins lucrativos. Embora estejam incluídos no contexto das características globais da inovação nos serviços, a inovação nos serviços sociais ou públicos especificamente constituem formas de natureza diferenciada, tendo em vista seus objetivos específicos centrados na prestação de serviços à sociedade que não são necessariamente comerciais.

A literatura sobre inovação nos serviços como um todo torna claro o debate existente sobre as nuances diferenciadas de sua conceituação e também sobre sua origem endógena ou exógena quanto às empresas. Uma perspectiva dessas inovações encontrada na literatura apresenta uma divisão entre três abordagens conceituais diferentes, como apontou Jeremy Howells (2010, p. 69): de assimilação, demarcação e integração. Em primeiro lugar, a abordagem denominada de "assimilação ou tecnologista" apresenta a força motriz e as formas de serviços de inovação como não endógenas, no sentido de que derivam da tecnologia e dos sistemas adotados externamente ao setor, em particular de computadores e outros equipamentos de Tecnologia da Informação. Esta visão adota o mesmo quadro conceitual e de mensuração utilizado pela teoria centrada nas empresas das indústrias manufatureiras, que considera a inovação nos serviços como resultado do desenvolvimento e uso de sistemas técnicos tangíveis. Por conseguinte, não considera aspectos não tangíveis do processo de criação inovadora.

A abordagem denominada de "demarcação" surge em oposição à anterior e tem em conta a especificidade dos setores de bens e serviços, através de uma forma diferenciada e comparativa daquelas utilizadas pela indústria transformadora, com abordagens orientadas para os serviços, no sentido de compreender estas diferenças. Esta visão levou a uma nova conceituação do processo de inovação, como endógena às atividades de serviços. O fato de que o produto é intangível e muitas vezes (nem sempre) produzido e consumido ao mesmo tempo, com o envolvimento dire- 
to do consumidor, torna difícil definir o momento em que houve mudanças nessa produção e consumo, que poderiam ser consideradas como inovação.

A partir dessa perspectiva, alguns autores tentam explicar as dificuldades, observando que muitas inovações feitas nessas atividades permanecem ocultas, uma vez que a produção não havia sido previamente conceituada e adequadamente medida e, portanto, a inovação não pode ser diretamente detectada. Devido a este fato, a inovação nos serviços é mais importante do que é tradicionalmente suposto e reconhecido e, além disso, sua relevância não se aplica apenas internamente ao setor, mas é importante para as outras atividades da economia.

Resumindo, a inovação nos serviços tem uma natureza diferenciada dos modelos existentes na indústria, como resultado de sua forma intangível, com ênfase em novas práticas e rotinas organizacionais, na dependência da interação com o usuário e, muitas vezes, com a coprodução entre produtor e consumidor. A simultaneidade de produção e consumo leva à incapacidade de estocar o produto, isto é, porque acarreta em elevado grau de perecibilidade (Howells, 2010). Esta abordagem é criticada por alguns autores, que evidenciam as semelhanças da inovação nos serviços com a nas manufaturas, e afirmam que suas premissas emergiram mais como uma rejeição ao paradigma tradicional, que considerava os serviços simplesmente passivos, dependentes de fornecedores e não inovadores.

Gallouj e Weinstein (1997) consideram que tanto a primeira quanto a segunda abordagem à questão da inovação nos serviços são tendenciosas, embora úteis para entender algumas das características dessas mudanças, pois a primeira perspectiva deixa de fora muitos aspectos, enquanto a segunda se concentrou principalmente na análise de estudos de caso e tipologias setoriais e, portanto, não tem um escopo maior para ser aplicado a outros serviços específicos. Esses autores constroem sua abordagem a partir de um modelo que representa um produto ou serviço através de suas competências, ou características técnicas e de outras características finais do sistema; desse modo, a inovação consiste em mudanças em um ou mais desses elementos (Gallouj e Savona, 2010, p. 28).

A terceira abordagem, denominada "integrativa", sintetiza e integra as duas primeiras, com a ideia de complementar esses conceitos com uma visão mais ampla dos aspectos tecnológicos intangíveis que podem ser aplicados tanto à indústria como aos serviços (Coombs e Miles 2000; Preissl, 2000; Drejer, 2004; Gallouj e Savona, 2010).

Mas esses autores reconhecem que houve mudanças fundamentais na maneira como as economias vêm se operacionalizando nas últimas décadas, o que requer outra forma de olhar para a inovação, particularmente através da crescente interdependência e integração entre produção e consumo de bens e serviços, bem como das novas estratégias competitivas. Esses eventos mudaram o foco da inovação, de novas tecnologias tangíveis para o foco de novos conhecimentos e da conquista de inovações das firmas em cadeias, redes e sistemas de tecnologia, que colocam as atividades manufatureiras e de serviços como fortemente inter-relacionadas. Mais 
do que isso, esta abordagem chama a atenção para o fato de que os efeitos das inovações nos serviços também são integrados, e percorrem todo o contexto social, tanto num ambiente limitado quanto em âmbito global. Esta maneira de analisar a inovação nos serviços é muito recente e existem poucos estudos empíricos sobre ela, de modo que ainda não está totalmente articulada, embora sejam estudos que busquem entender a associação entre inovação e desempenho econômico e social, por meio dessas inter-relações.

Mais recentemente, está surgindo uma nova abordagem que tem sido chamada de "segmentalista", que considera que a heterogeneidade dos serviços requer o estudo da inovação em subsetores específicos, que têm suas próprias características e não é possível construir um modelo abrangente que abarque todas as formas de inovação nos serviços sociais e econômicos públicos e privados. Há uma extensa literatura neoschumpeteriana focada na indústria, que distingue inovação de produto e processo, em parte devido ao fato de que outros tipos de inovação são menos facilmente identificados e medidos. No entanto, a própria tipologia schumpeteriana definiu a inovação de forma mais ampla e abrangente, incorporando a inovação multidisciplinar nos serviços, além da tradicional distinção processo-produto.

Como indica Schumpeter, resumidamente o conceito de inovação abrange as áreas de inovação de produto, inovação no processo, inovação de mercado, inovação de insumos e inovação organizacional. Com base nos conceitos deste autor, focados nas peculiaridades dos serviços, vários outros autores desenvolveram complementações às ideias, com foco nos serviços. Um desses novos conceitos refere-se à inovação $a d$ hoc, descrita como uma construção interativa ou social para resolver um problema específico imposto por uma situação social particular (Gadrey et al., 1995; Gallouj, 2000; Kon, 2016).

Assim como a inovação em serviços especificamente orientados para o mercado econômico, é possível caracterizar a inovação social nos serviços como a criação de relações públicas e privadas num contexto social com outros agentes, tais como fornecedores, clientes, autoridades públicas ou concorrentes, que são consumidores dos resultados sociais conjuntos. No que se refere à sua mensuração, em estudos recentes, este conceito esteve fortemente relacionado com a inovação nos meios empresariais ou organizacionais, o que acarreta a incorporação e uso de processos de coleta de informações e gerenciamento de decisões também baseadas em informações sociais. Estes processos de gestão da informação podem se referir quer ao ambiente de relações internas, como ao externo, isto é, estes últimos consistem num subconjunto da inovação organizacional. Isso implica que a inovação externa enfrenta as mesmas questões que a organização interna, no que diz respeito às dificuldades de mensuração e avaliação (Djellal e Gallouj, 2001).

A inovação social, embora nem sempre restrita à inovação nos serviços, na maioria das vezes é confundida com esse tipo intangível de produção e oferta de produtos oferecidos por diferentes agentes como o setor público, organizações e cidadãos, para atender às demandas da sociedade. Assim, a inovação nos serviços 
sociais visa aumentar o bem-estar social através de alternativas operacionais que aumentam a eficiência e a eficácia de seu desempenho, bem como a criação de valor social. Estas inovações se aplicam não só aos novos produtos sob a forma de serviços sociais, novas formas de acesso e distribuição de serviços, mas também às mudanças nos métodos sociais de governança, formas de organização e parcerias, que envolvem a esfera das práticas sociais e seus valores subjacentes (Crepaldi, De Rosa, Pesce, 2012, p. 11).

A implicação de incorporar um atributo social nesses serviços envolve não só o atendimento à demanda social, mas também as diferentes perspectivas de efetivação, as mudanças nas motivações e intenções, e também os impactos que as novas situações trazem para a sociedade. Nesse sentido, os objetivos e metas desses serviços incorporam valores, ideais e cultura em que esses serviços são inseridos e, portanto, a relação entre prestador de serviços e consumidor é muito diferente da natureza de outros serviços não sociais envolvidos em uma relação comercial de mercado.

Outra característica específica da natureza da inovação nos serviços sociais reside no fato de que, embora possa ocorrer em todos os setores da sociedade, sua dinâmica atende a pressões sociais e não de mercado, e também a mudanças institucionais e culturais. Mas é observada, em curto prazo, uma resistência generalizada a estas mudanças, não apenas por pressões ideológicas ou valores culturais, mas também pela incerteza ou medo da piora do bem-estar dos atores sociais consumidores (Crepaldi, De Rosa e Pesce, 2012).

A literatura sobre o tema mostra consenso sobre a conclusão de que na inovação dos serviços sociais o processo não é linear como na inovação tecnológica, mas sim interativo baseado na conectividade e nas interdependências, na cooperação, no intercâmbio de informações, na construção da confiança entre todas as relações e, portanto, sua introdução é mais complexa, porque requer negociação e cooperação entre os atores (Hochgerner, 2011; Howaldat e Schwartz, 2010; Bepa, 2011; Crepaldi, De Rosa e Pesce, 2012).

Esta conotação social de inovação em serviços encontra-se implicitamente na literatura que aborda particularmente algumas formas específicas de inovação de serviços em seu contexto mais amplo, tanto em áreas públicas como privadas: (i) condução da estratégia de planejamento de serviços que envolve mudanças na missão, objetivos, estratégias e racionalização dos agentes; (ii) mudanças nos produtos de serviços, representadas por novos recursos, funções e operações; (iii) mudanças nas formas de prestação de serviços, particularmente através da interação com os consumidores; (iv) mudanças nos processos internos de produção e de formas organizacionais; e (v) operacionalização através de inter-relações de sistemas integrados. Além disso, a inovação hoje não é apenas uma mudança momentânea, mas um processo contínuo, que pode ser incremental ou radical, embora constante (Gallouj e Djellal, 2012, p. 348).

Por outro lado, as inovações sociais ad hoc ajudam a produzir novos conhecimentos e novas competências que devem ser codificadas e formalizadas para que 
possam ser reduzidas a diferentes circunstâncias do ambiente social e à capacidade de adaptação às circunstâncias da época. Embora uma inovação $a d$ hoc não possa ser inteiramente reproduzível, uma vez que satisfaz a uma situação peculiar, basta que ela possa ser reproduzida indiretamente pela codificação e formalização das novas experiências e conhecimentos desenvolvidos nessa situação (Sundbo e Gallouj, 1998 e 2000). Também se argumenta que o processo de inovação leva à aprendizagem, o que não significa que a aprendizagem seja inovação, se não implicar uma nova mudança radical ou incremental no produto, no processo ou na organização (Drejer, 2004).

A inovação social é vista como uma espécie de inovação heterogênea que visa levar aos serviços sociais uma forma material (tangível) e é descrita como "colocar 'em ordem' as características do serviço, os especificando, tornando-os menos nebulosos, tornando-os concretos, dando-lhes forma" (Gallouj e Weinstein, 1997, p. 555). Um paralelo pode ser estabelecido entre este conceito e os métodos de codificação ou conhecimento explícito adquirido, que criam categorias de percepção que facilitam a classificação dos fenômenos, ou seja, esta inovação pode ser uma forma de tornar formais as ações até então informais ou conhecidas apenas implicitamente (tácitas). Esta inovação é também definida como ad hoc, uma vez que implica descontinuidade e dificuldades de difusão, uma vez que consiste em soluções específicas para ambientes sociais diversos e muitas vezes não reproduzíveis a problemas globais.

Outro conceito de inovação social surge para descrever inovações que consistem em detectar novas necessidades comunitárias e responder a elas através de um processo de acumulação de conhecimento e também de especialização em atividades de serviços. Estes tipos de inovação são descritos como potenciais, desde que a inovação efetiva será incorporada apenas como uma interação com o receptor do serviço, o que sugere que é apenas um caso especial de inovação ad hoc. Mas como evidenciado pelo formulador do conceito geral Gallouj (2000, p. 133), seus resultados essenciais são a abertura de novos mercados, a diversificação interna e externa do serviço, a renovação das modalidades de serviços, a criação de uma vantagem competitiva ou monopólio (ainda que no âmbito social), em termos de conhecimentos e competências.

A contribuição de novos conceitos sobre inovação nos serviços sociais chama a atenção para a multiplicidade de formas que podem tomar, de acordo com as diversas características das atividades de serviços nas quais elas ocorrem. Por isso, é muito discutida tanto a natureza quanto o grau de novidade que constitui verdadeiramente uma inovação. Drejer (2004, p. 14), acredita que a inovação em especialização é claramente uma inovação - também encontrada no pensamento de Schumpeter - quando detecta novas necessidades e as satisfaz, o que permite a abertura de novos mercados econômicos ou sociais. Salienta que a inovação nos relacionamentos enfrenta o mesmo problema que outros tipos de inovação orga- 
nizacional, no sentido de que podem ter um efeito adicionado significativo que, no entanto, é difícil de identificar e medir.

\section{O PROCESSO ORGANIZACIONAL DA INOVAÇÃO EM SERVIÇOS SOCIAIS}

Para compreender os diferentes processos de implementação de inovações nos serviços sociais, André Barcet procura responder à questão do que é a inovação em serviços de um modo geral. Ele mostra que a inovação radical significa uma ruptura com a tecnologia anterior, mas ressalta que, embora se considere que não haja inovação específica no produto de serviços, sempre é possível observar-se inovações incrementais em sua organização. Assim, é necessária a distinção entre as noções de inovação em organizações que prestam serviços e as inovações em serviços. Assim como na indústria de transformação, as organizações prestadoras de serviços consideram a inovação no processo, o que afeta suas habilidades, a organização interna de diferentes atividades e funções, as técnicas e tecnologias utilizadas bem como os resultados desses processos que são vendidos ou fornecidos a um agente econômico (Barcet, 2010, p.51).

Especificamente no contexto da inovação social em serviços, pode-se aplicar a ideia deste autor que constrói um novo paradigma descrevendo os processos dessas organizações de serviços, que contêm uma variedade de dimensões complementares entre si. O autor observa primeiro o mecanismo de criação de valor, ou "valor de uso", como conceituado pela teoria clássica, que difere do conceito da utilidade da teoria neoclássica e explica que este último conceito se refere à escolha e preferência individual, enquanto o anterior refere-se a uma visão mais global do processo de utilização do serviço, realizado tanto por um como por um grupo de usuários. Ele considera que a forma mais aceitável do processo que cria valor é a que envolve dimensões coletivas e sociais.

A outra dimensão complementar do paradigma refere-se à análise do próprio processo de utilização do serviço, que implica a análise do ato de consumo, seja individual, familiar, coletivo ou de organizações. Esse processo ocorre durante um período de tempo e no espaço, envolve atores, implica custos monetários e não monetários e produz resultados. Trata-se de resultados que são observados a partir de diferentes perspectivas de ação de produtores ou fornecedores, buscando obter os melhores resultados utilizando diferentes processos. Nesse sentido, inovação em serviços é a ação que causa efeitos incorporados em diferentes usos, sejam eles privados ou sociais. Isso requer que o produtor ou provedor identifique qual é o processo que produz novos resultados que serão incorporados à sua produção (Barcet, 2010, p. 52).

A terceira dimensão apresentada por Barcet refere-se a uma mudança geral em uma sociedade, qualificada como uma função ou funcionalidade que envolve a 
substituição dos fluxos de habilidades e serviços usados anteriormente. Em outras palavras, define a inovação como uma solução para um novo problema identificado, fornecido por uma atividade de serviços. O problema, que parte da demanda da sociedade, deve ser resolvido pelo provedor, de forma diferente da anterior.

Essas três dimensões consistem em diferentes maneiras de ver a mesma realidade, e definem a mudança de paradigma, que nem sempre resulta imediatamente na prestação do serviço, mas que pode ter efeitos futuros sobre a implementação e os resultados dos serviços. Assim, "conceber e criar uma inovação em serviços significa, portanto, definir e criar um processo de produção de efeitos e novos efeitos que respondam a constrangimentos ou problemas identificados" (Barcet, 2010, p. 53).

O novo paradigma de inovação no setor de serviços elaborado por Barcet (2010, p. 54) foca a ordem social, conforme interpretado a seguir. Consiste em um sistema de quatro camadas distintas de inovação, que interagem, em que cada camada permite a identificação das questões relevantes e os atores envolvidos na questão específica. A primeira camada foca o consumidor de serviços e leva à definição do uso e utilidade que os serviços devem fornecer ao cliente ou grupo de clientes (comunidade). Refere-se aos efeitos que o serviço deve causar, no que diz respeito à sustentabilidade dos seus impactos, aos custos adicionais associados à utilização do processo de serviço, à aprendizagem do cliente para a sua utilização e também à possibilidade de comparar os seus efeitos pelo cliente. Esta primeira camada é analisada como sendo a percepção de oportunidades de inovação, potencial de desenvolvimento e expectativas da sociedade.

A segunda camada refere-se à definição do produto que será oferecido, isto é, o conceito que o fornecedor deseja apresentar ao mercado. A inovação neste campo é sempre uma resposta deste fornecedor, que deve apresentá-la e induzir seu consumo como uma possível solução para as necessidades ou desejos manifestados pela sociedade. Consequentemente, existem muitas respostas alternativas como possíveis soluções, entre as quais o provedor seleciona a mais produtiva, que é distinta de outras soluções existentes. O produtor de serviços tenta garantir a durabilidade da inovação e, nesse nível, as ações visam identificar a oferta, a posição da oferta em relação à sua concorrência e a definição das principais características do serviço que a tornam original ou inovadora. Esta dimensão do modelo consiste em especificar os valores em que os serviços se baseiam em termos simbólicos, psicológicos, artísticos ou sociais.

Assim, nesta camada, no planejamento de uma inovação social nos serviços é essencial assegurar a consistência entre o produto final e o prometido, isto é, entre os valores proclamados pelo provedor e seus efeitos finais. Nesta fase definem-se também os valores econômicos do trabalho social e a relação custo/benefício, adaptados ao orçamento financeiro e a outros recursos produtivos tangíveis e intangíveis disponíveis.

Outra camada definida pela Barcet é dedicada à concepção do sistema de 
prestação de serviços, ou seja, a organização e distribuição da produção, e requer a especificação das etapas e fases necessárias para implementar o serviço. O desafio da inovação é, então, organizar as diversas atividades para integrar as dimensões heterogêneas das condições de operação do serviço social. Nesse sentido, é necessária a consciência de que a prestação de serviços sociais está sujeita a riscos dos vários ambientes locais onde é fornecida, que nem sempre podem ser controlados. O problema nessa camada é disponibilizar o serviço e planejar as informações, recursos e ações que devem acompanhar essa implementação.

Finalmente, a quarta camada destina-se a especificar os meios e recursos necessários e como eles serão alcançados interna ou externamente e ainda se a informação, os conhecimentos e as habilidades a serem desenvolvidos serão fornecidos pelo provedor e/ou consumidor, em uma coprodução. Isso é necessário porque muitos serviços podem exigir várias capacidades diferentes obtidas pelo envolvimento dos parceiros. Nesta fase, o desenvolvimento de certas inovações pode exigir um conhecimento histórico da tecnologia (path dependence, no conceito neoschumpeteriano) por parte de outro fornecedor já ativo e a inovação só pode acontecer sob a forma de parceria.

A relação entre as camadas, como descrita pelo autor, não é nem linear nem independente, e a possibilidade de responder (satisfatoriamente ou não) para resolver o problema em uma camada interfere nas escolhas e conceitos das outras camadas em uma interação constante.

Vários estudos destinados a explicar os processos de inovação nos serviços apontam que, nesses setores, a inovação é menos sistemática do que na indústria e as empresas de serviços raramente possuem departamentos específicos de pesquisa e desenvolvimento; além disso, a inovação é conduzida em conjunto com o processo de planejamento estratégico e com a formação e desenvolvimento de mercado (Coombs e Miles, 2000; Djellal e Gallouj, 2001). Esta forma de comportamento não deve conduzir à conclusão de que os setores de serviços são menos inovadores do que a indústria manufatureira, mas conduz à observação de que a noção de inovação deve ser mais bem compreendida e que existem outras formas de atividades inovadoras além dos estudos focados nos departamentos de P\&D. O ponto principal a observar é o fato de que o produto dos serviços, em sua natureza, consiste num processo contínuo e as diferentes formas de processos possíveis a serem implementadas devem ser observadas no que se refere ao conceito de inovação adotado (Taivonen, 2010).

Nesse sentido, nos departamentos de P\&D qualquer processo de inovação inclui o surgimento de uma ideia, o desenvolvimento da ideia e a sua implementação. Marja Taivonen (2010, p. 225) traz uma nova visão observando que nas empresas de serviços, a nova ideia pode ser desenvolvida simultaneamente à implementação, ou seja, a parte mais relevante do processo de inovação está integrada à prática de prestação do serviço. A autora vai mais longe e concluiu através de pesquisas empíricas focadas na produção do serviço, que uma parte significativa 
da inovação emerge sem esforços deliberados que visem à inovação. Isso pode ocorrer no caso de não ser uma ideia nova para um serviço que está sendo desenvolvido, mas uma nova prática ou um novo tipo de serviço, desenvolvido como uma resposta a alguma oportunidade percebida ou mudança, que atende às necessidades do consumidor.

A análise final de Taivonen (2010) determina três tipos de processos encontrados na inovação de serviços, cujo funcionamento pode ser extrapolado para o campo da inovação social. O primeiro caso refere-se à inovação como um projeto que se situa à parte da prática, que pode ser realizado antes desta. No contexto social, este tipo de procedimento é comumente realizado na fase de preparação da sociedade para a nova modalidade a ser implementada, que é realizada através de informação prévia aos consumidores sociais, a fim de facilitar a aceitação dessa inovação.

A segunda forma de desenvolvimento do processo de inovação a considera como um modelo de implementação rápida. Em termos sociais, a sua aplicação ocorre devido à necessidade urgente de resolver conflitos decorrentes do esgotamento de formas anteriores de prestação de serviços públicos, a fim de desbloquear rapidamente o acesso à sua aquisição, em tempos críticos cíclicos, ou quando há uma percepção de que a sociedade está preparada para assumir o novo processo. Finalmente, no terceiro processo, a inovação é implementada em sequência à prática de fornecer o serviço, quando as soluções não previamente deliberadas realizadas no curso do consumo de serviços, são posteriormente reconhecidas como tendo um potencial desenvolvimento futuro como uma inovação.

Portanto, estes modelos diferem uns dos outros em dois pontos: (i) se a inovação é intencionalmente procurada; ou (ii) se a parte principal do processo de inovação é efetuada antes que o novo serviço ou o serviço inovado seja colocado no mercado. Taivonen (2010) aponta que, além da inovação no processo de produção ou oferta do produto, a inovação nos serviços também inclui outros processos relacionados à inovação organizacional e de mercado, que muitas vezes se manifestam para integrar planejamento e execução e, podemos acrescentar, o mesmo é verdade no caso deste mercado se referir ao consumo de serviços sociais.

Outros aspectos da complexidade da inovação nos serviços resultam de vários agentes e caminhos envolvidos no processo: consumidores como fonte de ideias inovadoras, provedores de agentes como fontes de ideias que atuam em forma corporativa, trajetórias tecnológicas existentes, trajetórias intangíveis existentes, cursos administrativos e até mesmo os novos valores e prioridades da sociedade. $\mathrm{O}$ desenvolvimento de serviços para uma inovação social pode, portanto, começar a partir desses agentes e trajetórias e se consumar em uma série de padrões diferentes: o padrão clássico fordista ou neoindustrial, o padrão de serviços profissionais, o padrão de inovação estratégica organizada, padrão corporativo, o padrão artesanal e o padrão de redes (Sundbo, 2010, p. 282).

O processo de inovação em serviços é visto por Sundbo como tendo um cará- 
ter instável, que é explicado pela baixa capacidade humana para executar multitarefas simultaneamente, ou seja, o fato de que um grupo de prestadores de serviços pode ter que lidar com vários processos e vários interesses concorrentes que se desenvolvem simultaneamente e há dificuldades para equilibrar estas tarefas de forma adequada. Os vários interesses que interferem neste sentido se referem a aspectos como o grau de poder em sua ocupação, prestígio e posição individual, bem como tendências de expressividade pessoal e outras características que diferem entre os agentes humanos do processo, particularmente em uma interação social onde interferem crenças ideológicas individuais.

Dessa forma, na análise do quadro conceitual global de inovação em serviços, é relevante notar o papel específico do consumidor social no processo inovador, que em muitas produções é parte integrante do processo, influenciando a possibilidade de inovação. Na literatura, a integração do consumidor com o processo inovador pode ser resumida em cinco categorias, uma ideia que também pode ser extrapolada ao contexto dos serviços de inovação social: (i) o consumidor participa em todas as etapas do processo de inovação comercial ou socialmente distribuído; (ii) o consumidor participa na maioria dos estágios do processo e o fornecedor realiza a distribuição ou compartilhamento comercial; (iii) o consumidor reconhece a necessidade de inovação e cria a ideia para a solução da questão e, em seguida, o vendedor executa o resto do processo; (iv) o consumidor expressa a necessidade e o fornecedor executa o resto do processo; (v) o fornecedor participa em todos os estágios da inovação e o consumidor participa apenas como cliente comercial ou social (Kon, 2016).

Além do mais, a ação do consumidor neste âmbito social pode assumir muitas formas, desde sua ação como comprador do serviço - seja através do pagamento de impostos, taxas ou dinheiro ao setor privado -, bem como objeto de interesse, provedor de informação, perito e coprodutor. $\mathrm{O}$ grau de comunicação entre o prestador de serviços e o consumidor abrange uma série de intensidades, que vão desde a aquisição passiva de produtos, a informação e o feedback sobre aspectos específicos do serviço, uma ampla consulta sobre o seu impacto para a ação do consumidor, ou mesmo como parte integrante de todo o processo de desenvolvimento da inovação.

A tecnologia desenvolvida na atualidade facilitou a integração do consumidor ao processo, pela criação de hiper-realidades, simulações, testes de serviços, acompanhamento do comportamento do consumidor ou armazenamento de outras informações. Essas novas fontes de conhecimento tornaram-se relevantes para a inovação nos serviços, envolvendo a integração do consumidor neste processo através da interpretação e tradução da informação em ações inovadoras efetivas (Edvarsson et al., 2010, p. 309).

A integração do consumidor com o processo de inovação, portanto, é buscada como uma ferramenta que potencializa o poder do consumidor na distribuição do serviço no mercado social. Observando a inovação nesta perspectiva do envolvi- 
mento do consumidor, alguns autores mostram adicionalmente os diversos papéis que o consumidor pode exercer, em um envolvimento proativo no qual a proximidade ao consumo é buscada para com ela aprender e delinear novas necessidades e possibilidades de realização da inovação. Assim, o consumidor assume o papel de coinovador ou cocriador de novos serviços, direcionados a indivíduos, empresas ou serviços públicos (Edvardsson et al., 2010, p. 301).

\section{REDES DE INFORMAÇÃO, NOVO AMBIENTE E INOVAÇÃO NOS SERVIÇOS SOCIAIS}

As diferentes características do novo paradigma da inovação social incluem o uso intensivo de redes de distribuição ou disseminação para manter e gerenciar relacionamentos, utilizando meios móveis e fixos. A colaboração e as interações começaram a prevalecer em relações que muitas vezes se efetivam em cadeias voltadas para produção e consumo, onde as fronteiras não são claramente determinadas (Murray, Caulier-Grice e Mulgan, 2010).

A integração através de redes surge no contexto em que o cumprimento dos objetivos do novo paradigma de inovação social, como visto, envolve novos conceitos de mudança no processo ou serviços de produtos, que trazem mudanças organizacionais e nos padrões de financiamento, para lidar com novas formas de relacionamento e de busca de agentes para respostas aos problemas sociais. Por outro lado, o planejamento das ações envolve um diagnóstico determinado por meio de pesquisas e medições sobre a realidade que será objeto de intervenção, possibilitando a avaliação da possível aplicação de novas soluções ainda não testadas para resolver problemas em diferentes áreas espaciais e contextos sociais. Estas inovações sociais referem-se a novas práticas, novas instituições, novas técnicas, costumes e valores (OCDE, 2010; Hochgerner, 2011; BEPA, 2011).

A complexidade das ações que se relacionam com esses objetivos envolve a identificação e prestação de novos serviços que melhorem a qualidade de vida dos indivíduos e da comunidade, bem como a identificação e implementação de um novo tipo de processo de integração. Esta integração está relacionada com o mercado de trabalho, com a criação de novas competências, novos empregos e novas formas de participação. A implementação desta complexidade de ações só foi possível com o desenvolvimento de redes de informação que utilizam ferramentas informáticas.

Alguns autores observaram que a difusão da inovação social nos serviços ganhou maior impulso com o desenvolvimento das tecnologias de serviços que utilizam essas redes de informação, criando um novo ambiente econômico, cultural e social propício a essas mudanças e, mais do que isso, que são os principais instrumentos para o ajustamento da produção e da prestação de serviços coletivos à sociedade, em face da crescente demanda destes serviços, como resultado do au- 
mento populacional na maior parte dos países (Murray, Caulier-Grice e Mulgan, 2010; Crepaldi, De Rosa e Pesce, 2012; Kon, 2016).

Portanto, desde as últimas décadas do século XX tem-se verificado o surgimento da produção de serviços na forma de redes ou bens compartilhados por uma comunidade, que consiste em um novo modo de produção que evoluiu com o advento da Internet. Esta evolução se desenrola como uma comunidade aberta e pouco delimitadora que coopera instantaneamente, descoordenada e voluntária, para a produção de um bem informacional, cultural ou social. Como evidenciado por Kostakis (2011), esta forma de inovação deu origem a uma série de novas premissas no quadro teórico da Economia Política, particularmente depois do artigo de Yochai Benkler de 2002, "Coases Penguin, or Linux and the Nature of the Firm" que introduz o termo "produção de pares com base em bens comuns" (commons-based peer production), que pode ser interpretada como "produção cooperativa". Este termo, muitas vezes usado para descrever a produção social, define o novo modelo de produção socioeconômica em que a energia criativa de um grande número de pessoas é coordenada em grandes e importantes projetos, dentro da organização hierárquica tradicional, geralmente com a ajuda da Internet. Esses projetos são muitas vezes concebidos sem compensação financeira aos seus agentes e, portanto, são mais aplicáveis aos serviços públicos.

O artigo de 2006 de Yochai Benkler, intitulado "The wealth of networks: how social production transforms markets andf reedom" (A riqueza das redes: como a produção social transforma os mercados e a liberdade), cujo título se refere diretamente à "Riqueza das Nações" de Adam Smith, descreve uma forma de liberalismo econômico baseado na descrição da "mão invisível", que enfatiza a autonomia dos signos sociais para explicar a autorregulação do capitalismo, através da liberdade de concorrência e da lei da oferta e da procura. A nova "mão invisível” de Benkler não é mais dirigida pelo egoísta, mas pelas redes, que eram essenciais para o surgimento de uma nova etapa da economia chamada pelo autor de "economia da rede de informação”, cuja principal característica é proporcionar, para a ação individual e descentralizada, um papel maior do que na economia industrial (Benkler, 2002 e 2006).

O autor aponta duas transformações que operaram paralelamente, o que possibilitou a emergência desse novo sistema. A primeira grande mudança diz respeito à possibilidade de digitalizar a produção simbólica da humanidade, conceituada por Bourdieu (1974) como cultural, ideológica, de valores, intelectual ou social. Benkler (2006 e 2007) acrescenta que as redes informacionais que propagam bens simbólicos dão valor às formas de conhecimento que não são formalizáveis. Assim, o conhecimento torna-se a principal força produtiva de uma economia, aumentando a difusão da propriedade intangível e da produção de informação, através da manipulação de símbolos, exemplificados pelas ciências, serviços financeiros, contabilidade, de software e artes. Este autor aponta o potencial das redes de comunicação para a formação de uma sociedade livre e produtiva ("mão livre”), a partir 
de novas condições tecnológicas e econômicas, com base na economia virtual das comunicações.

A segunda transformação é a formação de um novo ambiente de comunicação preparado com base em processadores baratos, mas com alto poder de computação, interligados à rede, ou mais comumente associados à Internet, que auxiliam a criatividade humana, simplesmente pela disponibilidade de um capital físico representado por um computador e uma conexão em rede. Essa comunicação de baixo custo criou condições para colaborações sustentáveis e de compartilhamento de recursos, com base na produção cooperativa (commons), que têm características diferentes dos arranjos institucionais anteriores baseados na propriedade.

[...] Sugere que o ambiente em rede torna possível uma nova modalidade de organização da produção: radicalmente descentralizada, colaborativa e não proprietária; com base no compartilhamento de recursos e resultados entre indivíduos amplamente distribuídos e vagamente conectados que cooperam entre si sem depender de sinais de mercado ou de comandos gerenciais. Isso é o que eu chamo de "produção de pares baseada em bens comuns” (Benkler, 2007, p. 12. Tradução própria).

Assim, o capital físico das redes de computadores tem características e funções diferentes de outras formas de capital que moldaram a economia industrial no século XX. Benkler chama a atenção para o papel crescente da produção descentralizada e fora do sistema de mercado, particularmente nos setores social, da informação e da cultura, que Bourdieu (1974) denominava de mercado simbólico. Através de uma rápida transformação na produção e distribuição de informação, as tecnologias digitais proporcionam espaço adequado para socializar e organizar a formação de valores na economia e na sociedade. Benkler considera que um contexto repleto de commons é essencial para novas criações e inovações e cita os movimentos de software livre, como o YouTube, Slashdot, Wikipedia, entre outros, como exemplos de bem-sucedido commons e produção de pares. O software livre - definido como um conjunto de novas formas cooperativas de informação, conhecimento e produção cultural, em oposição aos mecanismos habituais de propriedade, hierarquia e mercado - é o exemplo mais característico desta produção de pares baseada em bens comuns (Benkler, 2007).

Voltando a atenção para a esfera pública, Benkler (2006) define esta nova forma de ação como o quadro de práticas que os membros de uma sociedade usam para comunicar questões que consideram de interesse público e que potencialmente requerem uma ação ou reconhecimento coletivo. A definição de esfera pública do autor nesta publicação é usada como uma referência ao conjunto de práticas que os membros de uma sociedade usam para comunicar questões que entendem como de interesse público e que requerem potencialmente a ação e o reconhecimento coletivo ou social. O autor salienta que, além disso, nem todas as comunicações sobre questões da esfera pública podem ser consideradas como parte da ação go- 
vernamental. Assim, as práticas que definem a esfera pública são estruturadas pela interação social entre cultura, organizações, instituições, economia e comunicações de infraestrutura técnica.

Portanto, a esfera pública não se restringe apenas ao setor público, mas é extrapolada aos casos de aumento da produção de informação através de relações não mercantis e não proprietárias, levando o assunto ao modelo de esfera pública sustentado por meios de comunicação de massa de grandes grupos privados de mídia e outros. Neste sentido, seria também possível a reconfiguração do setor público, através de processos de produção de informação via redes sociais, resultando na remodelação de formas prévias de comunicação com provedores e consumidores de serviços públicos da sociedade e com a expansão de novos serviços adequados para o novo modelo.

No que se refere especificamente ao setor público estatal, como salientam Micklethwait e Wooldrige (2015), as novas tecnologias possibilitam a reformulação da operacionalização desta esfera, de modo a corresponder às suas atribuições, em um cenário de esgotamento do modelo de Estado consolidado nas últimas décadas. Nesse modelo, os governos são pressionados por excesso de gastos originados pela necessidade de manter o bem-estar da população, que apresenta esperança de vida cada vez superior, em um ambiente de crise de credibilidade enfrentado pelos Estados, tanto em países ocidentais avançados quanto nos em desenvolvimento.

Nesse contexto, os países buscam não só a eficiência e eficácia no atendimento público (social) através da inovação em seus serviços, mas também definir os valores políticos transformados no século XXI. Os autores mostram que na atualidade a melhora da gestão pública estatal se dá pela exploração de novas tecnologias para aumentar a produtividade, desde que as transformações tecnológicas permitem a maior exatidão na coleta e a avaliação de dados, bem como na operacionalização do provimento de seus serviços (Micklethwait e Wooldrige, 2015).

Por outro lado, os processos de produção de informação através das redes sociais utilizadas pela esfera privada implicam a redistribuição do poder entre os grupos hegemônicos, bem como de outras questões que não são sujeitas a legislação ou outras instituições apropriadas. Assim, a produção e o intercâmbio de informações, bem como os recursos utilizados para esses processos, devem ser regulamentados pelo setor público, resultando na criação de serviços anteriormente não necessários. Nesse contexto, surgem questões no ambiente da informação, a respeito de que forma devem tomar as novas instituições a serem criadas e qual o escopo que a regulação deveria assumir: como bens públicos livremente utilizados por qualquer indivíduo, como bens comercializados no mercado, ou como filantrópicos fora do mercado (Kon, 2016).

Os conflitos decorrentes destas questões aplicam-se a várias camadas do ambiente de informação: aos dispositivos físicos e canais de rede necessários para comunicar, à regulação sobre a produção de conteúdo, aos recursos lógicos (softwares 
e padrões) necessários para traduzir o que os seres humanos querem comunicar uns aos outros, através de sinais que as máquinas podem processar e transmitir.

$\mathrm{O}$ ambiente para a inovação nos serviços sociais atribui atualmente um papel muito importante à tecnologia que conduziu à Internet como meio de comunicação, sem a qual, como salienta Benkler (2006), os projetos em ambiente de redes não teriam sido possíveis.

O processo de colaboração e parceria entre empresas existia antes das redes, mas essa nova possibilidade técnica transformou o papel econômico dessas atividades conjuntas.

Nem a tecnologia determinística nem aquela totalmente maleável estabelecem alguns parâmetros de ação individual e social. Ela pode fazer alguns relacionamentos, ações, organizações e instituições mais fáceis de realizar, e outros mais difíceis. Em um ambiente desafiador -- sejam os desafios naturais ou humanos - pode tornar alguns comportamentos obsoletos ao aumentar a eficácia de estratégias diretamente competitivas. No entanto, no âmbito da viabilidade - usos não impossibilitados pela adoção ou rejeição de uma tecnologia - diferentes padrões de adoção e uso podem resultar em relações sociais muito diferenciadas que emergem em torno de uma tecnologia (Benkler, 2006, p. 17. Tradução própria)

Assim, segundo este autor, o uso de tais tecnologias pode causar efeitos diferentes de acordo com suas formas de adoção e, particularmente na forma de economia de informação em rede, produzir e distribuir remotamente a informação estão ao alcance de muitos, de modo individual, coletivo ou social. A redução dos custos provocou significativas economias de escala e mudanças sociais, devido aos efeitos multiplicadores da inovação nos serviços, que são necessários para o desenvolvimento e implementação eficaz de sistemas em rede. A barreira tecnológica material que conduziu os processos industriais de informação antes do advento da Internet foi removida com esta nova tecnologia intangível e, assim, formas de comunicação fora dos sistemas de mercado se tornaram ainda mais importantes para o sistema de produção de informação.

Além disso, o fato de que essas atividades se tornaram disponíveis para todos os que estão conectados à rede em qualquer espaço abstrato, levou ao surgimento da agregação da ação individual, produzindo um efeito coordenado do novo ambiente de informação com resultados ampliados. A parceria socializada em grande escala, na produção de informação, conhecimento e cultura expandiu-se consideravelmente, não só no núcleo das plataformas de software, mas dentro de todos os campos de produção de informação, incluindo enciclopédias, notícias e comentários, mas também no ambiente de produção agrícola e industrial (Kon, 2016).

Outro aspecto relevante é o aparecimento da necessidade de mecanismos de filtragem, validação e síntese, como parte do comportamento conectado em parceria, e estes mecanismos assumem a forma de um conjunto de comunidades de in- 
teresse e associações que proporcionam uma pluralidade de caminhos de manifestação e validação. Estes efeitos aumentaram as necessidades de criação de meios inovados de implementação, coordenação e controle das novas atividades econômicas e sociais, que se disseminaram consideravelmente. Particularmente, o novo modelo de parceria em rede exigiu a expansão da inovação especificamente na esfera de serviços, para a adaptação de novas relações econômicas e para a expansão da demanda de bens materiais e ativos intangíveis (Benkler, 2006).

Em seu livro The Wealth of Networks, Benkler ressalta que o ponto central dessas inovações - decorrentes de novas condições tecnológicas que favorecem a produção colaborativa ou social - é que os processos de comunicação passam a conviver com o sistema de mercado e transformam a natureza da "mão invisível" de Adam Smith, e este sistema passa a ser guiado pelas mãos de funcionários em rede. No entanto, "o potencial de mudança dependerá da 'ecologia institucional' adotada pela sociedade, que pode beneficiar mais ou menos a riqueza das redes colaborativas" (Benkler, 2006, p. 116. Tradução própria).

Por sua vez, o novo sistema de redes interconectadas de transmissão de informações que se encontra na esfera pública como um todo, tem características muito diferentes da que se situa na esfera pública específica que foi dominada apenas por atividades de mídia (rádio, TV, jornais impressos, etc.). Primeiro, a infraestrutura de rede de informação distribuída e os custos decrescentes para se tornar um transmissor, levam a uma forma de ampla difusão, em contraste com os meios anteriores específicos centralizados de comunicação.

A emergência dessa nova visão em rede, no entanto, foi gradual e lenta, observando-se que desde meados do século XX a economia industrial e as teorias evolucionárias já enfatizavam o papel da informação no processo de produção e distribuição econômica das empresas. A evolução da economia industrial dependia consideravelmente da disponibilidade de informação, cuja aquisição era restringida pelo capital físico necessário à sua produção. Isto estimulou projetos de investimento de capital físico em tecnologia da informação, com o objetivo de orientar as atividades para a produção de mercado (Branco e Matsuzaki, 2009).

O modelo anterior de difusão de serviços sociais, baseado na existência de alguns poucos pontos de contato de produção e distribuição, devido ao alto custo de investimento, resultou em espaços topológicos de rede social tecidos pelos meios de comunicação, que se caracterizou pela presença de centros para a informação em comum e para canais de distribuição de mensagens fixas e fechadas, que foram limitadas pela extensão dos requisitos de capital para produção. No novo ambiente de informação em rede, as atividades de serviços que atuam na esfera pública para atender às demandas sociais, interligadas através da produção de pares baseada em bens comuns (commons), são por natureza menos dependentes do capital físico e, portanto, apresentam maior capacidade de expansão da produção, de crescente eficiência e consequentemente de bem-estar social (Branco e Matsuzaki, 2009). 
Assim, as condições e características da inovação nos serviços sociais que tornam a esfera pública interconectada mais eficiente e efetiva do que o modelo da esfera pública de mídia estão na ubiquidade da informação, na velocidade de processamento e na possibilidade de troca imediata de dados e opiniões, bem como pela capacidade de indexação de informações em bancos de dados. Os efeitos das redes de comunicação sobre as relações sociais têm sido muito complexas de identificar, porém um número de novas práticas sociais de produção neste ambiente criou novas oportunidades de intercâmbio de informações, conhecimento e cultura, que ampliou o papel da produção social, não só pelos indivíduos, mas através de esforços cooperativos.

No início do século XXI, as sociedades se desenvolveram intensamente no ambiente digital e na busca da sustentabilidade ambiental. Nesse contexto, as atividades multifacetadas dos diversos atores sociais - produtores, fornecedores ou consumidores de serviços sociais - interagem em diferentes níveis de governança para atender às necessidades da população. Dessa forma, a inovação em serviços tem sido o instrumento de consecução da inovação social, em seus objetivos de ampliação das possibilidades de atendimento às ampliadas demandas da sociedade.

\section{CONSIDERAÇÕES FINAIS}

Na medida em que a inovação social se caracteriza de forma mais contundente como modalidades de inovação nos serviços, esta última está incluída no contexto do desenvolvimento estrutural da sociedade. Assim, esse novo instrumento é criado para responder aos desafios atuais e futuros da sociedade, ou seja, responder a demandas sociais prementes que não são abordadas pelo mercado, na fronteira entre os campos social e econômico, porém dirigidos à sociedade como um todo. Nesse contexto, a inovação nos serviços sociais é responsável por melhorar os processos e os resultados da evolução social.

Muitas pesquisas mostram os fortes vínculos entre bem-estar e inovação nos serviços sociais, porque muitos processos e mecanismos na prestação de serviços sociais incluem diferentes atores que estão especificamente ligados a campos de atividades de serviços públicos estatais e setores ligados a atividades de bem-estar, tais como Saúde, Educação e outros. No entanto, a inovação social não só se dirige ao âmbito governamental, mas também dá lugar a experiências nos níveis de produção e consumo de mercado e está sendo utilizada nas esferas públicas privadas, pela sociedade civil e pela família, nos campos sobrepostos da economia social, do empreendedorismo social e das empresas sociais, em todo o mundo e em diferentes setores.

Desta forma, é necessário ressaltar a relação direta entre inovação em serviços e o contexto de desenvolvimento econômico, sob o qual a inovação e a tecnologia se tornam mais importantes na busca por elevação da produtividade e vantagens 
competitivas em serviços, que não só afetam as atividades manufatureiras, mas também todas as outras.

Portanto, esse tipo de inovação está apontando para novas relações socioeconômicas que podem ser vistas como uma economia social emergente, marcada pelo uso intensivo de redes disseminadas para sustentar e gerenciar relacionamentos, que renovam valores e culturas, e que enfatizam o papel das atividades de serviços bem como as formas específicas de suas inovações no âmbito de atendimento à parcela não mercantil da sociedade.

\section{REFERÊNCIAS BIBLIOGRÁFICAS}

BARCET, A. (2010) "Innovation in services: a new paradigm and innovation model”. In: Gallouj, F. \& Djellal, F. (eds.). The Handbook of Innovation and Services. Cheltenham, UK: Edward Elgar.

BENKLER, Y. (2002)."Coase's Penguin, or Linux and the nature of the firm". The Yale Law Journal, V.04.3 August.

BENKLER, Y. (2006). The Wealth of Networks: How Social Production Transforms Markets and Freedom. London: Yale University Press.

BENKLER, Y. (2007). “A economia política do commons”. In: Silveira S. A. (Eds..). A Comunicação Digital e a Construção dos Commons: Redes Virais, Espectro Aberto e as Novas Possibilidades de Regulação. São Paulo: Editora Perseu Abramo.

BEPA (Bureau of European Policy Advisers) (2011). Empowering people, driving change: Social innovation in the European Union. Luxembourg: Publications Office of the European Union.

BOURDIEU, Pierre (1974). "O mercado dos bens simbólicos”. In: Micelli, Sergio (org.) A Economia das Trocas Simbólicas. São Paulo: Perspectiva.

BRANCO, C. F. C. \& MATSUZAKI, L. (eds.) (2009). Olhares da Rede. São Paulo: Momento Editorial.

COOMBS, R. \& MILES, I. (2000) "Innovation, measurement and services: the new problematique". In Metcalfe, J.S. and Miles, I. (eds.): Innovation Systems in the Service Economy: Measurement and Case Study Analysis. London: Kluwer Academic Publishers.

CREPALDI, C., DE ROSA, E. e PESCE, F. (2012). Literature review on Innovation in Social Services in Europe. Sectors of Health, Education and Welfare Services. Milano: Instituto per la Ricerca Sociale.

DJELLAL, F. \& GALLOUJ, F. (2001). "Patterns of innovation organisation in service firms: portal survey results and theoretical models". Science and Public Policy, Vol. 28, No. 1.

DREJER, I. (2004). "Identifying innovation in surveys of services: A Schumpeterian perspective". Research Policy, Vol. 33, No. 3.

EDVARSSON, B., GUSTAFSSN, A., KRISTENSSON, P. \& WITELL, L. (2010). "Customer integration in service innovation”. In Gallouj, F. \&Djellal, F. (eds.) The Handbook of Innovation and Services. Cheltenham: Edward Elgar.

EUROPEAN UNION (EU) (2010). This is European Social Innovation, Belgium: European Commission.

GADREY. J., GALLOUJ, F., and WEINSTEIN, O. (1995). "New modes of innovation. How services benefit industries". International Journal of Service Industry Management, Vol.6, (3), pgs.4-16.

GALLOUJ, F. (2000). "Beyond technological innovation: Trajectories and varieties of services innovation”. In Boden, and Miles (eds.) Services, Innovation and the Knowledge Economy. London: Continuum.

GALLOUJ, F. and DJELLAL, F., (eds.) (2010). The Handbook of Innovation in Services, Cheltenham: Edward Elgar.

GALLOUJ, F. and SAVONA, M. (2010) “Towards a theory of innovation in services: a state of the art." 
In Gallouj, F. and Djellal, F. (eds.). The Handbook of Innovation in Services, Cheltenham: Edward Elgar.

GALLOUJ, F, and WEINSTEIN, O. (1997). "Innovation in services" Research Policy, Vol. 26.

HOCHGERNER, J. (2011). "The analysis of social innovations as social practice". In: Bridges, vol. 30.

HOWALDAT, J. and SCHWARTZ, M. (2010). Social Innovation: Concepts, Research Fields and International Trends. Aachen: RWTH Aachen University.

HOWELLS, J. (2010) "Services and innovation in services innovation: new theoretical directions". In Gallouj, F. and Djellal, F. (eds.). The Handbook of Innovation and Services. Cheltenham: Edward Elgar.

KON, A. (2016). A Nova Economia Política de Serviços, (The New Politic Economy of Services). São Paulo: Perspectiva.

KOSTAKIS, V. (2011). "Commons-based peer production and the neo-Weberian state: Synergies and interdependencies”. Halduskultuur - Administrative Culture 12 (2), 146- 161.

MICKLETHWAIT, John e WOOLDRIDGE, Adrian (2015). A Quarta Revolução. A Corrida Global para Reinventar o Estado. São Paulo: Portfolio-Penguin.

MURRAY, R., CAULIER-GRICE, J. \& MULGAN, G. (2010). The Open Book of Social Innovation. London: NESTA.

ORGANISATION FOR ECONOMIC CO-OPERATION AND DEVELOPMENT - OECD (2010). LEED Forum on Social Innovations. Geneve: OECD.

PREISSL, B. (2000). "European service sectors". In: Boden, M.\& Miles I. (eds.) Services and the Knowledge Based Economy. London: Continuum, pp.64-85.

SUNDBO, J. \& GALLOUJ, F. (1998). Innovation in Services. Oslo: SI4S Synthesis Papers No. S2.

SUNDBO, J., \& GALLOUJ, F. (2000). Innovation as a loosely coupled system in services. Oslo: SI4S Topical Paper, n.4.

SUNDBO, J. (2010) "The toilsome path of service innovation: the effects of the law of low human multi-task capability". In Gallouj, F. and Djellal, F. (eds.), The Handbook of Innovation and Services, Cheltenham: Edward Elgar.

TAIVONEN, M. (2010). "Different types of innovation processes in services, and their organizational implications”. In Gallouj, F. \& Djellal, F. (eds.) The Handbook of Innovation and Services. Cheltenham: Edward Elgar. 